\title{
Study on the Influence of Fast-growing Eucalyptus Planting on Reservoir Water Quality in Guangxi Based on N Stable Isotope Tracer Technology
}

\author{
Yanrong Zhao ${ }^{1, a^{*}}$, Fenggen Yang ${ }^{1, b}$, Jinchuan Guo ${ }^{2, c}$, Ronghui $\mathrm{Li}^{2, \mathrm{~d}}$ \\ ${ }^{1}$ School of Earth Science and Engineering, Hohai University, Nanjing 210098, China \\ ${ }^{2}$ Guangxi Hydraulic Research Institute, Nanning 530023, China \\ aryzhao98@sina.com, byangfg@hhu.edu.cn, gjc840413@sina.com, d29308914@qq.com
}

\begin{abstract}
Keywords: Fast-growing eucalyptus, N stable isotope, Tracer technology, Reservoir water quality Abstract. Lots of fast-growing eucalyptuses are planted in Guangxi because of their economic value. Based on the fertility characteristics of fast-growing eucalyptus and Guangxi soil nutrient status planting eucalyptus must pay attention to the application of fertilizer. Therefore, lots of nitrogen and phosphorus substances in fertilizer which go into the soil would be discharged into the surrounding reservoir through surface runoff, infiltration, water and soil loss, which would cause the reservoir eutrophication. Three typical reservoirs which there are a large numbers of planting eucalyptuses around are chosen as the research object. The thesis analyzes three typical reservoirs $\mathrm{N}$ pollution sources and the influence of eucalyptuses planting on reservoir water quality based on $\mathrm{N}$ stable isotope tracer technology on the basis of sample collection and the analysis of the conventional water chemical characteristics.
\end{abstract}

\section{Introduction}

Since 2001, Guangxi fast-growing eucalyptuses planting have had a fast development and formed the local ecological and economic features. However, large areas of cultivation of fast-growing eucalyptuses also brought many prominent environmental problems.[1] Due to the fast growth characteristic of fast-growing eucalyptuses it will absorb more nutrients.[2] Therefore, according the fertility characteristics of fast-growing eucalyptuses and Guangxi soil nutrient status, planting eucalyptuses must pay attention to the application of fertilizer in order to achieve business purpose. According to eucalyptus fertilization technology, generally it will apply fertilizer about $0.25-0.50 \mathrm{Kg} /$ pit before planting eucalyptuses and make trench fertilization one time after planting about 1-2 months. It should apply fertilizer in March to May or July to August one or two times each year in the second and third year of planting eucalyptus and the amount of fertilizer should be $0.25-0.50$ $\mathrm{Kg} /$ plant every time. Therefore, lots of nitrogen and phosphorus substances in fertilizer which go into the soil would be discharged into the surrounding reservoir through surface runoff, infiltration, water and soil loss, which would cause the reservoir water eutrophication. According to the present survey, it is found that the key factor which causes the reservoir water eutrophication is $\mathrm{N}$ in Guangxi eucalyptus forestland and which has a closed relation with $\mathrm{N}$ fertilizer applied to the eucalyptus. [3,4]

Therefore, Guangxi large-scale planting eucalyptuses problems which lead to the ecological environment crisis have aroused wide attention from social public. However, lots of fast-growing eucalyptuses are planted around many reservoirs, and as a result reservoir water quality is easily affected by the large amounts of nitrogen fertilizer applied to fast-growing eucalyptuses. Meanwhile, many reservoirs have the function such as irrigation and water supply in Guangxi and reservoir water quality requirements are strict. So, it is necessary to study the influence degree of nitrogen fertilizer in fast-growing eucalyptus forestland on the reservoir water quality and to know whether the nitrogen fertilizer is the main nitrogen source in the reservoir. Therefore, the thesis tries to research the influence of fast-growing eucalyptus planting on reservoir water quality in Guangxi through $\mathrm{N}$ stable isotope tracer technology.

Nitrogen source in water is complicated. It is necessary to use nitrogen isotope tracer technology to indentify nitrogen source. The principle of the application technology is that several kinds of main pollution 
sources have their respective characteristics of nitrogen isotopic composition and the $\delta^{15} \mathrm{~N}$ scope of different sources of nitrate is: precipitation for $-8 \% 0 \sim 2 \%$, chemical fertilizer for $-4 \% 0 \sim 4 \%$, mineralization of soil organic nitrogen for $4 \%$ o $8 \%$, domestic wastewater for $8 \%$ o $15 \%$, and human and animal waste for $10 \%$ 22\% . The nitrogen source in water can be deduced according to these values and the specific circumstances and water chemical characteristics.

As is known to all, there are two kinds of stable isotopes ${ }^{14} \mathrm{~N}$ and ${ }^{15} \mathrm{~N}$ in the nature, and their proportions in the atmospheric nitrogen separately are $99.635 \%$ and $0.365 \%$.[5,6] The $\delta^{15} \mathrm{~N}$ is calculated by Eq. 1 :

$$
\delta^{15} \mathrm{~N}(\%)=\left(\left(\mathrm{R}_{\text {sample }} / \mathrm{R}_{\text {atmosphere }}\right)-1\right) \times 1000 \text {. }
$$

In the Eq. $1, \mathrm{R}_{\text {sample: }}{ }^{15} \mathrm{~N} /{ }^{14} \mathrm{~N}, \mathrm{R}_{\text {atmosphere: }}: 0.365 \% / 99.635 \%=3.663 \times 10^{-3}$.

Therefore, three typical reservoirs which there are a large numbers of planting eucalyptuses around are chosen as the research object. The thesis analyzes $\mathrm{N}$ pollution sources of three typical reservoirs and eucalyptus planting forestland based on $\mathrm{N}$ stable isotope tracer technology and directly reveals the correlation between eucalyptus planting forestland and reservoir pollutants.

\section{The general situation in the research area}

Three typical reservoirs are respectively Gongjing reservoir, Qiufenglu reservoir and Shuanglong reservoir. Among them, the Gongjing reservoir is located in Xinfu town, Nanning city, Guangxi, and the reservoir catchment area is $0.68 \mathrm{Km}^{3}$, and combined capacity of storing is $380,000 \mathrm{~m}^{3}$; The Qiufenglu reservoir is located in Fuwang town, Qinzhou city, Guangxi, and the reservoir catchment area is $0.44 \mathrm{Km}^{3}$, and combined capacity of storing is $127,000 \mathrm{~m}^{3}$; The Shuanglong reservoir is located in Qingwan town, Beiliu city, Guangxi, and the reservoir catchment area is $0.33 \mathrm{Km}^{3}$, and combined capacity of storing is $252,600 \mathrm{~m}^{3}$.

\section{Samples collection on site and test work}

Researchers respectively completed the surface water collection and soil samples collection of the research area on November 5, 2013, and November 17, 2013 (because of the typhoon heavy rainfall an additional sample collected for comparison), and in May 2014.

Sample collection. In the three reservoirs water samples were respectively collected, and each sample volume is $2 \mathrm{~L}$. As shown in Fig. 1. It is necessary to research the geochemical characteristics of the soil samples in order to analyze the reservoir area surrounding soil influence on reservoir water quality. Specific work is: a number of vertical sections in the soil are laid out in the place of eucalyptus forestland near the reservoir and pine forestland far away from the reservoir, and largest section depth is $80 \mathrm{~cm}$. Meanwhile, different depth soil samples are collected and each soil sample weight is $2 \mathrm{Kg}$. As shown in Fig. 1.
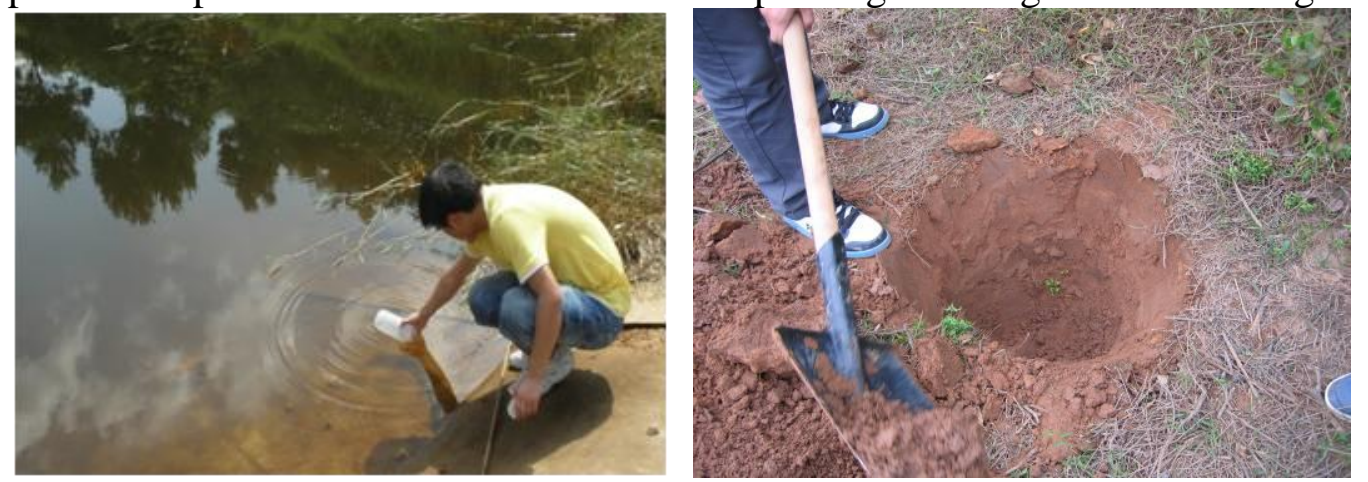

Fig. 1 Surface water and soil samples collection

Sample preprocessing and test. Water samples need to be preprocessed with $0.45 \mu$ filtration membrane in the water chemical analysis lab. After filtration was carried out, liquid need to be placed in the 
plastic bottles for test. Undisturbed soil samples on site need to be taken with polyethylene plastic seal bag. In the laboratory undisturbed soil samples need to be leached by $2 \mathrm{~mol} / \mathrm{L} \mathrm{KCl}$ solution and vibrated for 30 minutes, and centrifuged for 5 minutes. Then take the supernatant and test the $\mathrm{NO}_{3}{ }^{-}-\mathrm{N}$ and $\mathrm{NH}_{4}{ }^{+}-\mathrm{N}$ by flow injection apparatus. Use British IsoPrime 100 isotope mass spectrometer to test $\delta^{15} \mathrm{~N}$ of $\mathrm{NO}_{3}{ }^{-} \mathrm{N}$ in the water samples and undisturbed soil supernatant.

\section{Eucalyptus planting forestland influence analysis on reservoir water quality}

\section{The reservoir water quality classification feature}

Test the water samples for getting the value of $\mathrm{NO}_{3}{ }^{-}-\mathrm{N}, \mathrm{NH}_{4}{ }^{+}-\mathrm{N}$, total $\mathrm{N}$ and total $\mathrm{P}$. Then, make statistics and classify data according to the standard "Surface Water Environment Quality Standard Basic Limit" (GB3838-2002). The results are shown in Table 1.

Table 1 Nitrogen and phosphorus concentrations list of reservoir water samples (unit: $\mathrm{mg} / \mathrm{L}$ )

\begin{tabular}{|c|c|c|c|c|c|c|c|c|c|}
\hline No. & $\begin{array}{c}\text { Sample } \\
\text { name }\end{array}$ & Sampling site & $\begin{array}{c}\text { Sampling } \\
\text { date }\end{array}$ & $\begin{array}{c}\mathrm{NO}_{3}^{-} \\
-\mathrm{N}\end{array}$ & $\begin{array}{c}\mathrm{NH}_{4}^{+} \\
-\mathrm{N}\end{array}$ & $\begin{array}{c}\text { Total } \\
\mathrm{N}\end{array}$ & $\begin{array}{c}\text { Water } \\
\text { quality } \\
\text { grade }\end{array}$ & $\begin{array}{c}\text { Total } \\
\mathrm{P}\end{array}$ & $\begin{array}{c}\text { Water } \\
\text { quality } \\
\text { grade }\end{array}$ \\
\hline 1 & $\mathrm{SY}$ & Shuanglong & 2013.11 .5 & 0.19 & 0.22 & 0.41 & $\mathrm{II}$ & 0.03 & III \\
\hline 2 & QY & Qiufenglu & 2013.11 .5 & 0.26 & 0.65 & 0.91 & III & 0.01 & II \\
\hline 3 & GY-1 & Gongjing center & 2013.11 .5 & 0.27 & 0.87 & 1.14 & IV & 0.03 & III \\
\hline 4 & GY-2 & Gonging tail & 2013.11 .5 & 0.41 & 0.36 & 0.77 & III & 0.01 & I \\
\hline 5 & GM-1 & $\begin{array}{c}\text { Gongjing pine } \\
\text { forestland }\end{array}$ & 2013.11 .5 & 0.18 & 0.26 & 0.44 & II & 0.01 & I \\
\hline 6 & SY & Shuanglong & 2013.11 .17 & 0.21 & 0.18 & 0.39 & II & 0.06 & IV \\
\hline 7 & QY & Qiufenglu & 2013.11 .17 & 0.63 & 0.56 & 1.19 & IV & 0.02 & II \\
\hline 8 & GY-1 & Gongjing center & 2013.11 .17 & 0.41 & 0.76 & 1.17 & IV & 0.01 & I \\
\hline 9 & GY-2 & Gonging tail & 2013.11 .17 & 0.48 & 0.51 & 0.99 & III & 0.01 & I \\
\hline 10 & GM-1 & $\begin{array}{c}\text { Gongjing pine } \\
\text { forestland }\end{array}$ & 2013.11 .17 & 0.31 & 0.37 & 0.68 & III & 0.02 & II \\
\hline & & $\begin{array}{c}\text { Gongjing } \\
\text { upstream }\end{array}$ & 2013.11 .17 & 0.17 & 0.41 & 0.58 & III & 0.01 & I \\
\hline 11 & GA-1 & $\begin{array}{c}\text { Eucalyptus } \\
\text { forestland }\end{array}$ & & & & & & & \\
\hline 12 & SY & Shuanglong & 2014.5 & 0.61 & 0.77 & 1.38 & IV & 0.11 & V \\
\hline 13 & QY & Qiufenglu & 2014.5 & 1.15 & 0.77 & 1.92 & IV & 0.07 & IV \\
\hline 14 & GY-1 & Gongjing center & 2014.5 & 5.01 & 0.78 & 5.79 & V & 0.01 & I \\
\hline 15 & GY-2 & Gonging tail & 2014.5 & 3.94 & 0.82 & 4.76 & V & 0.05 & III \\
\hline
\end{tabular}

Compare to the standard GB3838-2002 and comprehensively classify water sample according to the total $\mathrm{N}$ and total P. The statistical results show that Shuanglong and Gonging reservoir water quality is IV $-\mathrm{V}$ grade, and Qiufenglu reservoir water quality is II - IV grade. Therefore, the three reservoirs water quality is relatively poor and is mainly IV - $\mathrm{V}$ grade.

Reservoir water and the soil nitrogen isotope characteristics analysis

Reservoir water nitrogen isotope characteristics analysis. Three reservoirs water $\mathrm{NO}_{3}{ }^{-} \mathrm{N}$ concentration and $\delta^{15} \mathrm{~N}$ test results are shown in Fig. 2 .

Gongjing reservoir nitrogen source analysis

In the pine forestland of Gongjing reservoir upstream water supply position a measuring weir was built. As a result, there was water inside the measuring weir on November 5 and 17, 2013 and two water samples were collected. So, the lowest $\delta^{15} \mathrm{~N}$ value of sample reaches $-6.64 \%$, and it indicates that the main nitrogen 
source in surface water of pine forestland is atmospheric precipitation. The result is consistent with pine forestland perennial no fertilizers. From the two test results of Gongjing reservoir water samples in November 2013, it can be seen that the value of $\delta^{15} \mathrm{~N}$ is between $-2.35 \%$ $+1.92 \%$. The result shows that nitrogen source is atmospheric precipitation and chemical fertilizer mixed source. However, the $\delta^{15} \mathrm{~N}$ values of two reservoir water samples in May 2014 reach 11.01\%o and 10.75\%, and the result show that the nitrogen source is animal waste. The conclusion is related with local farmers breeding duck from the beginning of 2014 in the reservoir. According to investigation, there were thousands of ducks in Gongjing reservoir in 2014. So the amounts of many ducks waste were very many in the reservoir, and which directly led the increase of $\delta^{15} \mathrm{~N}$.
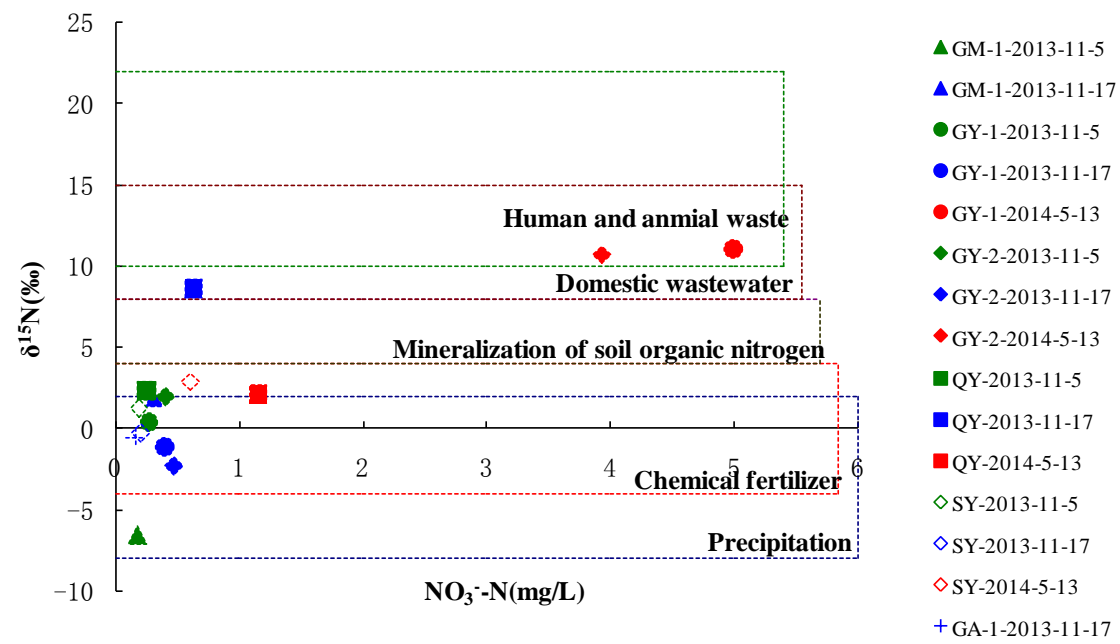

Fig. 2 Three reservoirs water $\mathrm{NO}_{3}{ }^{-}-\mathrm{N}$ concentration and $\delta^{15} \mathrm{~N}$ test results

Qiufenglu reservoir nitrogen source analysis

The $\delta^{15} \mathrm{~N}$ value of Qiufenglu reservoir water is between $+2.07 \%$ $+8.53 \%$. The test result indicates that the main nitrogen source in surface water is chemical fertilizer which mainly comes from the fertilizer used for planting fast-growing eucalyptus such as urea, nitrogen and phosphorus compound fertilizer, etc. The $\delta^{15} \mathrm{~N}$ values of Qiufenglu reservoir water sample which was collected on November 17, 2013 reach up to $8.53 \%$. The test result indicates that the main nitrogen source is domestic wastewater and animal waste pollution. Because a villager on duty lived beside the reservoir, the villager discharged much domestic wastewater into the reservoir. Moreover, fish and poultry were fed in the reservoir, and so animal waste is also an important nitrogen source.

Shuanglong reservoir nitrogen source analysis

The $\delta^{15} \mathrm{~N}$ value of Shuanglong reservoir water is between $-0.31 \%$ $+2.91 \%$. The test result indicates that the main nitrogen source in surface water is atmospheric precipitation and chemical fertilizer mixed source. Chemical fertilizer mainly comes from the fertilizer used for planting fast-growing eucalyptus. These fertilizers were partly absorbed by eucalyptus and mostly were discharged into the reservoir through surface runoff, erosion, rainfall infiltration and leaching, which led higher nitrogen concentration in reservoir water.

Nitrogen concentration and isotope characteristics analysis of the soil in the eucalyptus forestland around the reservoir. Nitrogen concentration and isotope test results of soil samples which were collected on November 5, 2013 are shown in Table 2.

The results of Table 1 and Table 2 show that the $\mathrm{NO}_{3}{ }^{-}-\mathrm{N}$ and $\mathrm{NH}_{4}{ }^{+}-\mathrm{N}$ concentration of undisturbed soil are several times to dozens times than the reservoir water. So, the nitrogen source of reservoir water came from soil through eluviation, and the $\mathrm{NO}_{3}{ }^{-} \mathrm{N}$ and $\mathrm{NH}_{4}{ }^{+}-\mathrm{N}$ of soil mainly came from eucalyptus forestland fertilization and might partly come from mineralization of soil organic nitrogen. Moreover, according to the nitrogen isotope test results of the undisturbed soil, it can be seen that the main nitrogen source of the pine forestland soil around Gongjing reservoir is atmospheric precipitation. The result is consistent with pine forestland perennial no fertilizers. The main nitrogen source of the eucalyptus forestland soil around Gonging 
reservoir is atmospheric precipitation and chemical fertilizer. Meanwhile, the main nitrogen source of the eucalyptus forestland soil around Qiufenglu reservoir is also atmospheric precipitation and chemical fertilizer. However, the main nitrogen source of the eucalyptus forestland soil around Shuanglong reservoir is atmospheric precipitation, and it shows that sampling site may not apply fertilizer.

Table 2 Nitrogen concentration and isotope test results of the undisturbed soil

(Sampling date: on November 5, 2013)

\begin{tabular}{|c|c|c|c|c|c|c|c|}
\hline No. & $\begin{array}{c}\text { Sample } \\
\text { No. }\end{array}$ & Sampling site & $\begin{array}{l}\text { Depth } \\
(\mathrm{cm})\end{array}$ & $\begin{array}{l}\mathrm{NH}_{4}{ }^{+}-\mathrm{N} \\
(\mathrm{mg} / \mathrm{Kg})\end{array}$ & $\begin{array}{l}\mathrm{NO}_{3}{ }^{-}-\mathrm{N} \\
(\mathrm{mg} / \mathrm{Kg})\end{array}$ & $\begin{array}{l}\delta^{15} \mathrm{~N} \\
(\%)\end{array}$ & Nitrogen source \\
\hline 1 & GM-2 & $\begin{array}{l}\text { Gongjing } \\
\text { pine } \\
\text { forestland }\end{array}$ & 0 & 8.31 & 2.41 & -12.34 & precipitation \\
\hline 2 & GT7-1 & \multirow{5}{*}{$\begin{array}{l}\text { Gongjing } \\
\text { reservoir } \\
\text { right bank }\end{array}$} & 0 & 6.79 & 20.5 & 1.46 & $\begin{array}{l}\text { Precipitation and } \\
\text { chemical fertilizer }\end{array}$ \\
\hline 3 & GT7-2 & & 20 & 5.23 & 10.2 & 0.55 & $\begin{array}{l}\text { Precipitation and } \\
\text { chemical fertilizer }\end{array}$ \\
\hline 4 & GT7-3 & & 40 & 6.67 & 3.40 & -4.80 & precipitation \\
\hline 5 & GT7-4 & & 60 & 5.52 & 2.08 & -2.96 & $\begin{array}{l}\text { Precipitation and } \\
\text { chemical fertilizer }\end{array}$ \\
\hline 6 & GT7-5 & & 80 & 5.33 & 2.39 & -1.82 & $\begin{array}{l}\text { Precipitation and } \\
\text { chemical fertilizer }\end{array}$ \\
\hline 7 & QT-1 & \multirow{2}{*}{$\begin{array}{l}\text { Qiufenglu } \\
\text { reservoir } \\
\text { right bank }\end{array}$} & 0 & 9.10 & 12.8 & -3.92 & $\begin{array}{l}\text { Precipitation and } \\
\text { chemical fertilizer }\end{array}$ \\
\hline 8 & QT-2 & & 30 & 9.18 & 4.25 & -6.89 & precipitation \\
\hline 9 & ST-1 & \multirow{2}{*}{$\begin{array}{l}\text { Shuanglong } \\
\text { reservoir } \\
\text { right bank }\end{array}$} & 0 & 8.35 & 6.03 & -8.88 & precipitation \\
\hline 10 & ST-2 & & 30 & 8.09 & 2.61 & -9.43 & precipitation \\
\hline
\end{tabular}

\section{Conclusions}

The conclusions through the research of Shuanglong, Gongjing and Qiufenglu reservoir water samples and soil samples can be gotten as follows:

(1) According to the total $\mathrm{N}$ and total $\mathrm{P}$ classification method, the statistical results show that Shuanglong and Gonging reservoir water quality is IV - V, and Qiufenglu reservoir water quality is II - IV. Therefore, the water quality of three reservoirs is relatively poor and is mainly IV $-\mathrm{V}$.

(2) The nitrogen sources of Gongjing reservoir water are complicated. The main nitrogen source of pine forestland around the Gongjing reservoir is atmospheric precipitation. The result is consistent with pine forestland perennial no fertilizers. From the two test results of Gongjing reservoir water sample collected in November 2013, it can be seen that nitrogen source is atmospheric precipitation and chemical fertilizer mixed source. However, the $\delta^{15} \mathrm{~N}$ values of reservoir water samples in May 2014 show that the nitrogen source is animal waste. The conclusion is related with local farmers breeding duck from the beginning of 2014 in the reservoir. The $\delta^{15} \mathrm{~N}$ of Qiufenglu reservoir water indicates that the main nitrogen source is chemical fertilizer. However, the $\delta^{15} \mathrm{~N}$ values of Qiufenglu reservoir water sample which was collected on November 17, 2013 reach up to $8.53 \%$. The test result indicates that the main nitrogen source is domestic wastewater and animal waste pollution. Because a villager on duty lived beside the reservoir, the villager discharged much domestic wastewater into the reservoir. Moreover, fish and poultry were fed in the reservoir, and so animal waste is also an important nitrogen source. The $\delta^{15} \mathrm{~N}$ of Shuanglong reservoir water is between $-0.31 \%$ $+2.91 \%$. The test result indicates that the main nitrogen source in surface water is atmospheric precipitation and chemical fertilizer mixed source. 
(3) The $\mathrm{NO}_{3}{ }^{-}-\mathrm{N}$ and $\mathrm{NH}_{4}{ }^{+}-\mathrm{N}$ concentration and the $\delta^{15} \mathrm{~N}$ value of the soil show that the nitrogen sources of the soil around the reservoir mainly come from atmospheric precipitation and fertilizer.

(4) This thesis applies the $\mathrm{N}$ stable isotope tracer technology to research $\mathrm{N}$ pollution sources of three typical reservoirs and analyzes the eucalyptus planting influence on reservoir water quality. Through the analysis and research, the results of the research are consistent with the actual situation. Therefore, the method of applying $\mathrm{N}$ stable isotope tracer technology to research the $\mathrm{N}$ pollution source is feasible and credible.

\section{Acknowledgements}

This research work was financially supported by Ministry of Water Resources Public Welfare Projects (Grant No. 201301044), The Natural Science Foundation of Jiangsu Province (Grant No. BK20131367) and China Scholarship Council.

\section{References}

[1] Guoqin Huang, Qiguo Zhao, Acta Ecologica Sinica. 18 (2014) 5142-5152. (In Chinese)

[2] Changshang Yang, Lifeng Tan, Modern Agricultural Sciences and Technology. 6 (2010) 238-239. (In Chinese)

[3] Bichang Nong, Ying Zhang, Jizhao Cao, Shaolin Deng, Jin Wang, Xinfeng Wei, Guangxi Forestry Science. 3 (2006) 147-150. (In Chinese)

[4] Jiechun Zhao, Yuzhong Li, Yamashita Ichiji, Chunying Xu, Qiaozhen Li, Xiaofang Jia, Chinese Agricultural Science Bulletin. 18(2010) 374-378. (In Chinese)

[5] T.H.E.Heaton, Chemical Geology, 1 (1986) 87-102.

[6] Aravena R, Evans M L, Cherry J A, Ground Water, 31 (1993) 180-186.

[7] Wassenaar L, Applied Geochemistry, 10 (1995) 391-405.

[8] C.Kendll, D.H.Campbell, D.A.Bums, J.B.Shanley, S.R.Silva, C.C.Y.Chang, Biogeochemistry of Seasonally Snow-covered Catchments (Proceedings of a Boulder Symposium), 228 (1995) 339-347. 